PRE-PUB VERSION: 7/18/18

\title{
Black Holes and Purple Squirrels: A Tale of Two Online Labor Markets*
}

\author{
Steve McDonald, North Carolina State University \\ Amanda K. Damarin, Georgia State University - Perimeter College \\ Jenelle Lawhorne, North Carolina State University \\ Annika Wilcox, North Carolina State University
}

\begin{abstract}
The Internet and social media have fundamentally transformed the ways in which individuals find jobs. Relatively little is known about how demand-side market actors use online information and the implications for social stratification and mobility. This study provides an in-depth exploration of the online recruitment strategies pursued by human resource (HR) professionals. Qualitative interviews with $61 \mathrm{HR}$ recruiters in two southern US metro areas reveal two distinct patterns in how they use Internet resources to fill jobs. For low and general skill work, they post advertisements to online job boards (e.g., Monster, CareerBuilder) with massive audiences of job seekers. By contrast, for high-skill or supervisory positions, they use LinkedIn to target passive candidates - employed individuals who are not looking for work but might be willing to change jobs. Although there are some intermediate practices, the overall picture is one of an increasingly bifurcated "winner-take-all" labor market in which recruiters focus their efforts on poaching specialized superstar talent ("purple squirrels") from the ranks of the currently employed, while active job seekers are relegated to the hyper-competitive and impersonal "black hole" of the online job boards.
\end{abstract}

Keywords: hiring, recruitment, job search, labor markets, Internet, stratification

* Data collection was supported by a grant from the College of Humanities and Social Sciences at North Carolina State University and from the American Sociological Society's Fund for the Advancement of the Discipline. We thank Steve Vallas and Ofer Sharone for their detailed commentary and advice on earlier drafts of this paper. We also thank our many interviewees who made this research possible by sharing their thoughts and experiences with us. 


\section{INTRODUCTION}

The advent of job search and recruiting websites such as Monster, CareerBuilder, and Indeed, as well as professional social media websites like LinkedIn, has fundamentally transformed the matching of workers and employers in the US. Four out of every five job seekers use the Internet to search for jobs (Green, Li, Owen, \& de Hoyos, 2012; Smith, 2015). Roughly the same percentage (84) of employers use the Internet to advertise and recruit for job openings (SHRM, 2016). These changes have profound implications for social stratification and mobility that researchers are only beginning to understand. Optimistic projections about the capacity for the Internet to empower the workforce through expanded access to opportunities (Feldman \& Klaas, 2002; Freeman, 2002) have given way to concerns about the uneven benefits associated with digital connectivity (Autor, 2001). Online job finding seems likely to accelerate the formation of "winner-take-all" markets (Frank \& Cook, 1996) that primarily benefit elite workers and generate greater competition for jobs among most other workers (Autor, 2001; Sharone, 2017).

Our research is an attempt to clarify how digital technologies have transformed labor market institutions. Whereas recent research has examined how job seekers understand and experience the online labor market (Gershon, 2017; Sharone, 2017), we focus on the demand side of the market. How do organizational actors understand and use online technologies for filling job openings? What digital practices do they engage in when attempting to identify, recruit, and evaluate potential job candidates? How do these meanings and practices vary depending on the different types of positions they are attempting to fill?

We address these questions by analyzing the experiences and practices of human resource (HR) professionals involved in recruiting. Despite their importance to the hiring process, relatively little is known about how these recruiters use web-based data and applications to fill 
job openings (Klotz, da Motta Veiga, Buckley, \& Gavin, 2013). Evidence from interviews with $61 \mathrm{HR}$ professionals in two Southern US metropolitan areas reveals how Internet job matching technologies have led recruiters to follow two primary strategies for filling jobs. The first involves posting ads and sorting massive pools of applications for general and low skill positions. The second involves targeted recruitment of passive ("non-searching") talent to fill high-demand, high-skill, and supervisory positions. Despite some hybrid practices, these two general patterns reveal a unique form of labor market dualism. Organizational actors use distinct online tools and practices to evaluate and allocate different segments of the workforce. These practices point to heightened employment competition for much of the workforce and significant employment advantages for those workers who display ideal digital signifiers.

\section{INTERNET SEARCH AND RECRUITMENT}

The everyday functioning of job markets has undergone a major transformation since the inception of the World Wide Web and popularization of the Internet. Starting around 1995, these technologies gave rise to a whole range of new market intermediaries, or entities that "facilitate, inform, or regulate how workers are matched to firms" (Autor, 2001, p. 1). Previously, common intermediaries included newspaper help-wanted advertising, interpersonal networks, union hiring halls, and recruiting firms. Today, these are joined by online job and résumé posting boards (e.g., CareerBuilder.com, Monster.com), specialty job boards sponsored by educational, professional, and industrial institutions (e.g., the ASA job board), social networking websites (e.g., LinkedIn, Facebook), and search engines (e.g., Google). Use of these online tools has become normative. Internet access among US adults has increased from about 50 percent in 2000 to nearly 90 percent in 2016 (Pew Research Center, 2017). The vast majority of job seekers use the Internet to search for employment opportunities (SHRM, 2016). About one out of every five external job 
matches in the United States occurs through online job posting boards (Bonet, Cappelli, \& Hamori, 2013) and over 80 percent of employers engaged in active recruiting use social media sites to do so (SHRM, 2016).

Previous research has examined Internet job finding mostly from the supply side of the workforce, noting the impact of the digital divide on economic inequality (DiMaggio, Hargittai, Neuman, \& Robinson, 2001; Hargittai, 2011). Internet-based job searchers tend to be younger, more urban, more advantaged (in terms of education and skills), and more likely to be currently employed than offline searchers (Fountain, 2005; Green et al., 2012; Kuhn \& Skuterud, 2004; Nakamura, Shaw, Freeman, Nakamura, \& Pyman, 2009). Relative to offline job searches, Internet-based job search often leads to increased odds of finding a position, reduced unemployment durations, and/or higher quality jobs (Burke \& Kraut, 2013; DiMaggio \& Bonikowski, 2008; Suvankulov, Chi Keung Lau, \& Ho Chi Chau, 2012), though other findings suggest that the benefits of Internet job finding are more modest (see Fountain, 2005; Kuhn \& Skuterud, 2004; Van Hoye, van Hooft, \& Lievens, 2009). Several early studies of Internet searching found that employers use the Internet to recruit for high skilled positions, but turn to other methods to recruit for low-skilled jobs (Cappelli, 2001; S. McDonald \& Crew, 2006; Niles \& Hanson, 2003).

Much of the existing literature has emphasized the empowering potential of online labor market tools (Sharone, 2017). Certainly, the Internet has expanded the availability of information about job openings and job candidates. Websites such as Monster and CareerBuilder serve as storehouses for information about thousands of jobs and job seekers globally. Aggregators like Indeed.com search out and re-post job advertisements found on company job boards across the Internet. LinkedIn, the professional social media website, allows workers to post their work 
profiles for others to view and interact with. Employer organizations also post information about job openings, and often about their own employees, on company websites. These knowledgeenriching resources may help remedy problems of information-boundedness found in traditional job markets and potentially improve job matches (Autor, 2001). Furthermore, increased access to online information about worker qualifications could allow employers to avoid traditional reliance on "old boy networks" and focus more on job skills when making hiring decisions (Freeman, 2002). Likewise, Internet job matching could render invisible the ascriptive and status characteristics of job seekers (Viswanath, Kosicki, Fredin, \& Park, 2000; Walther, 1996), allowing for a more diverse workforce and a more meritocratic job market (Feldman \& Klaas, 2002; Freeman, 2002).

Recently, Sharone (2017) has argued that the spread of the Internet operates as a "doubleedged sword" for labor market participants. It offers benefits in the form of increased exposure for potential job candidates, but also makes it easier for employers to use digital signals to stratify segments of the workforce. Advancements in computing power, speed, memory, and algorithmic sophistication have led to exponential increases in the capacity of organizations to process data retrieved from the Internet. This has led to what Fourcade and Healy (2017) refer to as the "institutional data imperative" that encourages organizations to collect large quantities of digital information to classify and rank workers, customers, and potential employees. For example, organizational actors perceive social media posts as valid indicators of mental ability, personality, and worker productivity (Berger \& Zickar, 2016; Stoughton, Thompson, \& Meade, 2013). Organizations are seeking algorithmic tools that would effectively translate digital footprints into personality scores (Faliagka, Tsakalidis, \& Tzimas, 2012; O’Neil, 2016). 
Internet technologies have thereby accelerated the creation of "winner-take-all" labor markets (Frank \& Cook, 1996) in which payoffs are determined by rankings, top participants earn the bulk of the rewards, and small differences in characteristics tend to be associated with large differences in outcomes (Frank \& Cook, 2013). Increased access to digital signals and means to evaluate those signals has created opportunities for systematic ranking of the workforce based on perceptions of "ideal performativity" reflective of optimal employment competency and organizational fit (Carr, 2016; P. McDonald \& Thompson, 2016). Workers with atypical or deviant digital signals suffer by comparison (Ruggs, Walker, Blanchard, \& Gur, 2016), which forces them to be more proactive and often settle for significantly reduced labor market returns. Superstar workers benefit from the exposure brought on by Internet connectivity by becoming passive beneficiaries of targeted recruitment (cf., S. McDonald, 2015). Although screening stigmatized job applicants and recruiting privileged ones are not new practices, advances in algorithmic tools have expanded their scope and efficiency and amplified their consequences for marginalized segments of the workforce (O’Neil, 2016; Eubanks, 2017). Headhunting and talent poaching are also not new (Finlay \& Coverdill, 2002), but growth in online worker databases and application tools have enabled a broader range of organizations and recruiters to identify ideal performers (Coverdill \& Finlay, 2017).

The "double-edged" character of online job finding has therefore led to a form of labor market polarization which is distinct from that suggested by existing theories. Earlier scholarship on labor market segmentation distinguished between primary and secondary sectors based on whether workers could access stable employment queues and upward mobility in large hierarchically-organized firms (Doeringer \& Piore, 1971; Hudson, 2007). This theory's utility has declined alongside the replacement of intra-organizational job ladders with "boundaryless" 
careers and network-mediated organizations (Powell, 1990; Arthur \& Rousseau, 1996).

Economic theory of skill-biased technological change (SBTC) also addresses labor market polarization, suggesting that income inequality has expanded due to rising wage premiums associated with high tech computer skills (Bound \& Johnson, 1992; Autor, Katz, \& Kearney, 2008). However, SBTC is unable to account for how demand for skill is socially-constructed by organizational actors (Hanley, 2014; Rivera, 2016). Moreover, the theory focuses on skill and productivity, leaving the job matching process opaque. We argue that much of today's polarization is predicated on distinct sets of rules (logics, tools, and practices) for securing employment through online job market intermediaries.

Our account of labor market polarization builds on recent research which reveals: 1) how unemployed workers deal with stigma as part of the online job finding (Gershon, 2017; Sharone, 2017), 2) how résumé signals and interpersonal interviews are used to assess candidate fit in elite labor markets based on cultural similarity (Rivera, 2016; Coverdill and Finlay, 2017), and 3) how digital tools and cultural assumptions are used to categorize market actors (Kiviat, 2017; O'Neil, 2016). Collectively, these studies point to the bifurcated character of job matching in the new economy. However, much remains unknown about how demand-side agents interpret and construct distinct online labor markets through strategies for candidate searching and screening (Klotz et al., 2013).

\section{DATA AND METHODOLOGY}

The data presented here come from 61 qualitative interviews with human resource professionals, an important group to study because of their critical role as labor market intermediaries. Our interviews were conducted from 2014 through 2016 in Atlanta, GA and the Research Triangle area (Raleigh-Durham-Chapel Hill) of North Carolina. These southern metropolitan areas are 
excellent places to study hiring practices because they are fast growing in terms of population, employment, and diversity. They also contain high proportions of professional and technology jobs. Respondents were recruited mainly through attendance at HR professional events; a few come from respondent-suggested referrals. Individuals were eligible to participate if their jobs involved recruitment and screening. Interviews were semi-structured and centered on hiring practices (job posting, sourcing applicants for openings, and targeted recruitment) as well as screening (sorting, interviewing, and assessing candidate quality), though the focus for this paper is on the former. Interviews lasted more than one hour on average and were audio recorded (in all but one instance). In the Appendix (see Table A1), we include details on the personal and employment characteristics of each interviewee.

We followed a grounded theory approach to the collection and analysis of these data (Hess-Biber \& Leavy, 2011). Data collection and analysis proceeded reflexively, as initial interviews led to a more focused set of inquiries. The lead author used open coding procedures to assign the various elements of the text data to categories. Then a focused coding stage examined the various connections among the codes. We developed analytic memos that highlighted the emergent themes; these themes were studied in greater detail through additional data collection. Data collection ceased when codes reached saturation and when relevant themes were fully explored.

Our methodological approach emphasizes the subjective experiences of the interviewees and makes no claims to generalizability of those experiences. However, theoretical sampling strategies were employed to generate a broad pool of respondents. For example, given concerns about missing the experiences of underemployed HR professionals, researchers attended and recruited respondents from "transition" support groups of HR professionals to supplement the 
sample. The final sample includes HR professionals in a variety of settings including non-profit organizations, private companies of all sizes, staffing agencies, and colleges/universities. The sample also represents a broad range of industry settings, including (but not limited to) real estate, law, finance, health care, energy, engineering, manufacturing, and private services. These HR professionals recruit talent for part time and full time jobs; temporary, permanent, and "temp-to-perm" jobs; low, middle, and high wage jobs. Our analysis centers on several prominent themes that emerged throughout the interviews.

\section{THE "BLACK HOLE" OF MASS POSTING SITES}

Mass job and résumé posting websites are the best-known and longest-standing feature of online labor markets. Among them, the most prominent are Monster.com, which as of this writing boasts over five million jobs on file and 29 résumés uploaded every minute, and CareerBuilder, with three million jobs posted monthly and 150 million candidate profiles ${ }^{1}$. The professional networking application LinkedIn, the job aggregator Indeed.com, and a wide array of other posting sites (e.g., government-sponsored) have similar functions. By compiling voluminous information about available jobs and job seekers into searchable databases—with added features like targeted social media distribution, email alerts, and auto-filled applications- these sites have made it much easier for employers to publicize openings and for workers to learn about and respond to them. Sharon, a non-profit sector recruiter, explained the implications of this transition.

Everything is electronic. So, for people who are applying online, it's maybe a 3-4 minute process. It's not like what it used to be where you'd send in your résumé in the mail, fill in an application, send it in. It's a couple of clicks. You fill out your name, your address, your email address. You attach your résumé, this is what I'm applying for and it sends it to us. It's a much easier process. It could be done day, night, whenever it's convenient for job seekers, so more are applying.

\footnotetext{
${ }^{1}$ See http://promotions.monster.com/keywordjobsearch and https://hiring.careerbuilder.com/.
} 
Sharon links the relative ease of applying for jobs online to the tremendous increase in the number of applications for any given job opening. Many of our other respondents also described receiving a high volume of applicants from the mass posting boards.

\section{Going with the Flow}

This increased volume of applications is a mixed blessing for recruiters. Jonathan, an experienced recruiter in a university setting, explained how these sources are extremely useful for generating "flow" or high numbers of job candidates for a posted opening.

The thing with Career Builder and Monster and those generic type [of websites] ... those are great sites if you want to generate a ton of flow. Because they do that. They clearly do that.

A high flow of applicants is particularly useful when recruiters are hiring quickly, continuously, or for numerous openings. However, the large number of applications can be overwhelming. Linda, a recruiter for an engineering company, explained, "If I go out and look for an accountant tomorrow ... [using] Career Builder, I'll get 1000 résumés within a couple of weeks.” The increased volume also results in numerous applications that do not fit the job descriptions. Many interviewees were confounded by candidates who chose to apply for jobs for which they were clearly not qualified. IT recruiter Jessica stated that when she used CareerBuilder, "I would post for a data warehouse engineer, and I would get warehouse workers applying for these jobs." Many complained that people "don't read the job description," but some suggested that applicants are so desperate for work that they will jump at even the slimmest chance. Others suggested that applying for unattainable jobs might be a strategy of avoiding work while completing the work search activities required for receipt of government unemployment benefits. 
Those respondents who relied on mass posting sites described sorting through scores of unqualified candidates as a "frustrating" effort at "weeding out a lot of junk." According to Margaret, a staffing agency recruiter...

It bogs everything down so much that it's hard for us to even figure out who the good candidates are...internal recruiters will tell me, "Oh yeah, we got 5000 responses to that posting." There's no way. How do you sift through all that information?

The problem of information overload elicited varied responses. Some recruiters tried to avoid the mass posting sites entirely, but this was not always possible or prudent. In certain circumstances, they needed an immediate flow of candidates to make multiple or rapid hires. In addition, posting on some mass posting sites (US.jobs, state websites, and CraigsList.org) is very inexpensive or free, and use of government sites may be mandated by employer policy. Further, some respondents felt that they had little control over where their job postings went. Betterresourced employers typically have an applicant tracking system (ATS), an elaborate software program that manages job requisitions, postings, applications, and related tasks; many recruiters reported that their ATS systems automatically fed their job advertisements to the mass posting boards. In addition, their posts on their own websites would be "scraped" and redistributed by aggregators like Indeed that "spider out" to collect job listings from across the web.

Rather than reducing application volume, many of our participants use software applications to work around the problems it creates. ATS systems can be set up to receive applications and feed them into a database where they can be keyword-searched, which speeds the sorting process. ATS and some mass posting sites can be configured so that applicants are required to answer job-specific screening questions that help rank their eligibility. Barbara, an HR generalist at a small utility company, said she used CareerBuilder to receive applications... because we use the screening questions ... to help kind of weed people out ... I have all the questions ranked, so it gives me a percentage. This person scored 100, this person 
scored $50 \%$. And, you can set up Career Builder to only give you people who get $80 \%$ or better ... so you don't even see the résumés [for the rest].

This and other reports show that just as digital technology spawns information overload by easing the job application process, it also alleviates it to some extent by reducing the effort required to screen resulting applicants. It is not clear whether the problem of labor market information-boundedness is actually resolved or simply shifted from a human condition to a technological one.

\section{Low Skill and High Competition}

Mass posting sites were also favored for advertising certain types of jobs. First, they remain the central online recruitment tool for work with low or generic skill requirements. This includes entry level and often low-paying positions in manufacturing and the professional services. Mass posting sites are useful for such jobs because they facilitate speedy hiring in high turnover situations and because recruiters and hiring managers tend to view workers as non-essential and easy to replace. Specific skills are often less important, as is evidenced in agency recruiter Caitlin's rationale for mass posting an immediate-need temporary receptionist position:

That [job] was something we could post an ad for. There's usually a large number of candidates, because it was pretty generic. Just somebody who felt comfortable at the front desk. For that type of position, it's really more about the volume. You might have to ... bring lots of different people in in order to find that person who is a good fit for the company ... [For more specialized roles] I really could tell by the LinkedIn profile or by the resume if they're going to be a good fit based on their background. For this one it was more [necessary to be] meeting them in person and knowing that personality or culture fit.

In addition to this relatively generic labor, mass posting sites are used as starting points in searches for high demand talent. Recruiters indicated that Monster or CareerBuilder might uncover a uniquely qualified worker, especially one new to the area. However, more often than not these tools were supplemented with more active and nuanced recruitment practices. 
The prominence of mass posting sites impacts job seekers in important ways. Most HR professionals agreed that the increased volume of applicants for any given position has resulted in heightened competition for employment opportunities. Jonathan explained how the increasing ease of applying online has affected competition for jobs.

Now, the downside to the technology and all the online stuff is that it could be overwhelming. Say somebody applies to a job and that company or that organization gets hundreds and hundreds of résumés, which it's pretty easy to do when everything is online. It's really fairly easy to apply like that. You can inadvertently get buried in the pile.

Despite the increase in unqualified candidates, recruiters have nonetheless seen an increase in the absolute numbers of qualified applicants for jobs. As Jonathan's comment suggests, the stack of applicants has gotten taller, ultimately reducing the odds that any one job candidate will rise to the top.

\section{Répondez S'il Vous Plaît}

Recruiters tend to hold a dim view of the employment prospects of job seekers who rely primarily on mass posting sites. "A lot of the online postings are black holes. There's a lot of people looking and everybody has a computer and everybody is just blasting out their résumé," explained Nancy, a recruiter from a private staffing agency. Samantha, another agency recruiter, echoed this by noting that sometimes applicants "may feel that they're just putting their résumé into an empty abyss of résumés, and sometimes that's the truth." This "black hole" characterization partly speaks to concerns about increased competitiveness. As individuals are competing with more people for each mass posted job opening, these sources may be of little help in actually securing employment. Sarah, in her 40s, had been attempting to break into the HR profession mid-career and expressed her own frustration with searching for employment via online applications: 
I have to do all these electronic applications but I have no faith that I will get a job because I've applied for something electronically...I've applied for 50 or 60 jobs and I've heard from none of them... Well, I could spend between 20 and 40 minutes on an online application to find out nothing. To hear nothing at all.

Sarah's comment illustrates the problems of heightened competition and limited opportunity on the online job boards, but her criticism extends to another important aspect of the "black hole" simile. Specifically, recruiters and job seekers alike loathe the de-personalized nature of online job applications. Not only are workers unlikely to hear a positive response, they are unlikely to hear any response at all. Recruiters explained that they are often unable to respond to also-ran candidates because of the sheer volume of applicants in each candidate pool. Moreover, they often sympathize with job seekers mired in the online marketplace. Dan, a midcareer recruiter from a private employment agency, reflected:

People will post jobs and there will be hundreds of applicants and no one will hear back, so it's that feeling of inadequacy. People are feeling, "nobody wants me, nobody wants me." I feel like I'm very marketable...why don't people want to talk with me? I'm like, "well, the pool of candidates you're competing against has ten times the number of what it used to be." People can't get back to you quick enough. It depersonalizes it a lot.

Dan's statement implies that the increased competition for jobs on mass posting websites, coupled with a lack of personalized response from employers, negatively impacts mental health by generating feelings of inadequacy and isolation among job seekers.

\section{A MARKET FOR PASSIVE CANDIDATES}

For many HR professionals, the work of filling job openings extends well beyond posting ads and receiving applications through mass posting boards. Interviewees also described their efforts to identify "passive" candidates to supplement applicant pools. Charles defined passive candidates as follows:

A passive candidate is somebody who is sitting there doing their job, and doing a good job. And is not actively - not unemployed... But they are a passive candidate in the sense 
that if somebody that they trust said, "I thought about you when I heard about this [job]," they might listen and they might respond.

Other recruiters indicated that passive candidates are employed workers who dissatisfied with their jobs. Mary, an HR manager at a small private firm, expressed this sentiment most succinctly:

A lot of times people sit in a job that they feel mediocre about for a long, long time before something happens and they decide that they're going to look for a new job. And, if you can catch them in that period of time when they don't really like what they're doing, but they haven't crossed the bridge yet over to, 'I'm going to leave and look for something else," you can get them when they're really ripe.

Mary's reference to mediocrity implies that workers can become bored with their work or frustrated with a lack of opportunities for personal or professional growth. Still, the decision to move is an important one and can take a long time. Mary's comments suggest that this critical shift in outlook, which she likens to crossing a bridge and the ripening of fruit, is a cumulative process rather than one that is triggered by a single event. And yet, passive candidates must be plucked when they are willing to make a move, but before they are snatched up by competitors.

Passive candidates are highly valued commodities in the recruiting world. According to Lisa, an HR supervisor for a large private firm, "usually the best candidates, you're going to be kind of stealing them from another company." Many recruiters had difficulty explaining exactly why passive candidates are so desirable. Some viewed passive candidates as "tried and true" with "good job longevity," someone who is "not going to job hop" or "just go to the next dollar." Others reasoned that because passive candidates are currently employed, it is safe to assume that "whatever they're doing, they're doing well" and they are "contributing some kind of value." These comments imply that passive candidates maintain superior qualities of performance, experience, and dedication. 
For other recruiters, it was a lack of availability that made passive candidates attractive. "It's kind of like dating," explained Brian, a recruiting coordinator for a private staffing agency. "You want the girl that's not available. There's a reason she's not available. We found that those top folks, they're just very, very good at what they do." Brian's comments reveal that unavailability serves as a signal that these workers are "top" quality and leaders in their respective fields. Joe, a recruiting supervisor at a large public university, similarly compared passive candidates to industry leaders: "When you think about the best professionals you may know or the best researchers you may know, many of them probably aren't looking on job boards. They're not looking for work." Passive candidates fit Joe's mental image of how the "best" workers operate. The standard strategy of posting openings on job boards is therefore unlikely to yield a pool of high quality candidates.

\section{The Stigma of Active Search}

Many interviewees described the superiority of passive candidates by describing the suboptimal qualities of active job seekers. For example, "If they're looking, why are they looking? They're either miserable, they don't like their job, they're unemployed, they got fired," explained Rick, a recruiter at a private hospital. These negative signals suggest that the individual is a poor-quality worker or has a bad disposition. Alicia, a talent director for an accounting firm, claimed that active search could indicate that candidates:

weren't a good fit [with their previous or existing employers] ... for a variety of reasons. They couldn't hang with the pace and the demands ... If there were some performance issues like that; if they didn't play nicely in the sand box and they were causing - they were one of these negative employees, the disengaged employees that's causing more drama and upheaval than is helpful. Sometimes those are the people that end up in the active bucket, and those are the ones we're trying to avoid. 
Edward, a recruiting supervisor at a private firm in the health services industry, asserted that actively looking for work could be an indication of "running from something." When asked what that meant, he explained that individuals often prefer to leave bad working environments - e.g., ones in which they had to work long hours and where managers were unresponsive to feedback rather than trying to fix those environments. He felt that "maxing out" on advancement potential would be a more legitimate reason to seek a new job. In short, active search is clearly stigmatized among recruiters and results in a wide range of inferences about worker quality and personality.

Recruiters often assume that passive candidates are employed. In fact, the individuals we talked to sometimes conflated the unemployed with workers who are employed but looking for work. This was illustrated above by Charles' description of passive candidates as, "not actively not unemployed." Equating active search with unemployment is significant because unemployment carries a stigma among recruiters. "When you're unemployed, it raises those questions. Why aren't they working? What happened at their last job? You'd much rather go with what you think is a sure thing and that's someone that's currently working," offered Betty, a young recruiter fresh out of college. Heather, an HR generalist in fast food, wanted her management-track hires...

to be employed in some way, shape, or form, when I bring them onboard ... because that is demonstrative of your work ethic ... I get the idea of making your job search your fulltime job ... But I would prefer you do something ... Are you volunteering, are you giving back to the community in some way, how are you filling your time? Are you watching Days of Our Lives all day, or General Hospital?

Betty sees the unemployed as risky hires, while Heather suspects that they are lacking in work ethic. Other interviewees claimed that unemployment is not as serious a concern for workers who have been laid off from their jobs, as even the best workers can experience layoffs. Still, 
more than one mentioned that layoffs are not random and could reflect worker quality if companies use them strategically to eliminate their substandard workforce. Some noted that many unemployed candidates tried to avoid stigma by reporting that they had been laid off when in fact they had been fired: "everybody says they got laid off these days, it's just what they say." This perceived deception no doubt makes it easier to dismiss unemployed candidates of all stripes. Thus, whether it signifies a specific trait like laziness or simply the risk of yet-unknown problems, unemployment is often enough for recruiters to remove individuals from applicant pools.

Kevin's experience illustrates how powerful the stigma of unemployment can be. He is an HR director in a medium sized technology firm:

When I was out looking for a job, I got contacted by a recruiter from a very large recruiting firm that was looking to fill a lead HR role for a company in this area. ... The phone call went very well and then somewhere along the line in the conversation, it came up that I was no longer at my last employer and she [the recruiter] was taken aback. She goes, "Oh, you're no longer working." I said, "No, I'm not. I've been gone there for X amount of months." She said, "Well they're only looking for-they're only going to consider people that are currently working for this position." ... I think that's not unusual.

Based on his credentials and the phone screen, Kevin appeared to be qualified for the job. It was only his status as unemployed that got him removed from the applicant pool. Regardless of its precise causes or meanings, unemployment functions as a strong negative signal of worker quality. As active search is often equated with unemployment, passive non-searchers are viewed as the surest source of talent.

\section{Variation in Targeted Recruitment}

Recruitment of passive talent requires extra effort and therefore tends to be reserved for specific types of job openings, particularly for high-demand occupations. As specialty recruiter Ryan put it, the decision to source passive candidates is partly determined by "what the market is like ... if 
the market is more favorable to the employee or the job searcher, you're going to tend to talk to more passive folks. If the market is tighter and employers are being a lot more particular, it's harder for the employee to find work, then you're going to have more active candidates in the market." Our respondents identified information technology, various engineering specialties, and registered nursing as fields that require targeted recruiting since virtually all qualified talent is employed.

The decision to recruit passive talent is also determined by the availability of candidate information. Susan, a law firm recruiter, explained:

I definitely do it for paralegal ones. ... Most of the paralegals, you can find them on LinkedIn. ... It's kind of hit or miss with the administrative individuals. ... I don't think they're always looking on LinkedIn to find a job.

Susan can recruit passive candidates for paralegal positions in part because she is connected to many legal professionals on LinkedIn, which makes it easy to search and identify individuals who might be ready to change jobs. This is not the case with administrative assistants, whom she perceives as having a weaker LinkedIn presence.

Passive candidates are also recruited to fill high-level executive and managerial positions. Mark, an experienced recruiter for a large private corporation, explained that executives 'aren't people that you generally can post a position and they're going to apply. It's almost all going out and sourcing." Joe explained that he engages in targeted recruitment of high-level university personnel because he views these positions as particularly important to the organization.

Which positions are considered those key, primary positions? Stands to reason you wouldn't likely do the same effort of recruitment for a position that's relatively easy to fill that has little impact on the university, but one that's very difficult or one that's a key strategic position at the university is certainly one that we would want to spend more time on. ... [The] focus is [on] those key strategy positions here at the university, going all out for those searches. 
In addition to being deemed more "strategic," executive positions are also usually staffed continuously. If incumbents perform poorly, the search for their replacements occurs while they are employed and without their awareness. This makes confidentiality vital. As IT recruiter Jessica explained in reference to a current opening:

... we don't want to really advertise ... and throw it out there. One of the reasons being an existing internal employee ... I printed out a bunch of job descriptions and took them with me to [a professional group meeting] because I don't want it on the job boards, I don't want it on LinkedIn. I don't want this individual to see us actively [sourcing]. There are some of those positions that come up that are kind of hush hush.

The idea of executives actively searching for jobs may also be viewed as inappropriate, even comical: Dorothy, a young recruiter for a private company, noted: “you really don't see directors out on Career Builder saying, 'Hey I need a job.' [laughs]."

Highly paid workers therefore appear to exist in a truly distinctive job market, where changing jobs typically involves passive recruitment. To assess variable recruitment strategies across salary levels, the Atlanta interviewees were asked to think about several recent job openings and how they were filled (see Figure 1). HR tends to post job advertisements for jobs almost irrespective of their income level. Employee referrals are a common means of recruiting workers for low wage jobs. Sourcing of passive candidates is especially common for high wage positions, with nearly 70 percent of jobs openings above $\$ 75,000$ recruited in this way. This pattern is consistent with previous research showing substantial amounts of referral hiring into low wage jobs versus recruitment of passive candidates into high wage jobs (see S. McDonald, 2015).

\section{[Insert Figure 1 about here]}

Organizational variation in 1) preferences for passive talent and 2) targeted recruitment of passive talent is also striking. Passive candidates were preferred by 75 percent of the respondents 
from third-party staffing/recruiting agencies, compared to only 18 percent of respondents from non-profit and government organizations. Preferences for passive candidates among for-profit companies fell in the middle (50 percent for respondents from small and medium-sized firms; 36 percent for respondents from large firms). Figure 2 shows that the preferences of these organizations matched their strategies. Over 80 percent of third-party staffing/recruiting agencies actively targeted passive talent as part of their recruitment efforts. Only 11 percent of non-profit and government organizations did the same. These results show that attitudes and engagement strategies vary substantially across employment sectors.

\section{[Insert Figure 2 about here]}

\section{Fishing for Passive Talent}

Beyond applicant quality and occupation type, there are some practical reasons for sourcing passive candidates. For instance, some interviewees described the practice as a way of closing market information gaps. According to finance recruiter Lisa, "you have to proactively source people because otherwise everyone could just post and then everyone would apply, but we obviously know that's not the case. Every single person in the world does not apply to your job. So you have to proactively go out and look for these individuals." Similarly, recruiter Monica stated that she had to source passive candidates because her company's lack of name recognition made it hard to attract active job seekers.

Further, the Internet (generally) and social media (specifically) have made the identification of passive candidates much easier. Experienced HR professionals explained that prior to the world wide web, recruitment of passive talent was largely facilitated by personal networks: recruiters maintained files and Rolodexes filled with potential candidates they had previously met, and phoned them as the need arose. The Internet transformed this work by 
providing more extensive information about and greater access to the working population.

LinkedIn especially has served as a game changer. Nancy explained:

As a recruiter, I'm very dependent upon LinkedIn. That's pretty much the white pages [laughs] for professionals. I'm able to - just by simply searching a company — find people that have worked within different industries, with target companies, with competitors and it's a way for me to be able to have easy access to a lot of people. Because something that is very important in my line of work is knowing [the passive candidates]. A lot of times the active job seekers that are applying to postings. They may not be the people you want to meet with.

Nancy and others use LinkedIn to identify passive candidates because it provides a huge database for the workforce, especially the professional class. LinkedIn allows recruiters to scan their own network connections to find prospective job candidates. For a fee, LinkedIn can also be used to identify individuals who have specific skill sets, participate in professional working groups, or work for specific industries and companies, all of which can be critical information when attempting to poach talent from competitors. Brian offers more detail on the use of LinkedIn to identify passive candidates at his staffing agency.

LinkedIn is our biggest tool. We'll go out and pull people from companies. Whoever we're doing the search for, whatever company, we'll ask them, "Where do you see most of the talent from in your area? Where are they coming from? What companies?" Then we'll target those companies ... [and their] current employees and then keyword search for the title. Then start calling these folks.

Brian and others obtain initial lists of candidates by searching the employees of their clients' top competitors. Some recruiters felt that this approach was effectively prohibited by company policies or industry norms, and hence used industry-based rather than company-specific searches. A few interviewees mentioned that they had taken short courses and received certificates for conducting advanced talent searches on LinkedIn and other social media. 
HR professionals pride themselves on being able to identify passive candidates who are in the ready-to-transition stage. Kenneth provided an example of how he found his job in a private recruiting/consulting firm:

I was passive-I was on LinkedIn just to network with peers in the industry. I wasn't looking until—until I was really looking. I remember that Wednesday night and Thursday morning, I changed a few things on my profile to make it look active, added some more detail so that it would show up in more searches. ... At that point I was working as a specialist in learning and development, so I added a little bit more of that in my profile. My résumé itself didn't change, but my profile changed. I added some of the keywords that I knew that people would search for.

On Friday morning, Kenneth was contacted by a recruiter that led to his current job. His story suggests that signals of the readiness to move can be quite subtle, such as adding skills, professional group affiliations, or updating other information (e.g., job titles, work experience) on LinkedIn profiles. Simply changing one's profile can move individuals closer to the top of recruiter's search results and convey openness to new opportunities. Kenneth's description also reveals how the distinction between active and passive searching is no mere dichotomy. Individuals may consider themselves not to be on the market but nonetheless engage in subtle market behaviors, perhaps as a way of avoiding the stigma of actively looking for work.

\section{Wooing Passive Candidates}

One key challenge for recruiters of passive talent is "selling" candidates on the idea of making a job change. Dan offered his insight on how recruiters tend to approach these individuals.

They'll send you a little cursory note that says, "I found your information" or "Someone gave me your name and I have this opportunity..." It's usually very non-invasive. It's like, "If you know of anybody that might be interested..." They're fishing to see if you are [interested]. ... Often times, [if you respond] it's like, "Well, I'm glad that you're interested because I was really hoping you would be." Then if you're not, hopefully [the recruiter will] get a referral out of it. 
Dan's comment suggests that initial communications are subtle and indirect. The recruiter is hoping that the person they have contacted will be interested in the job, but asks if that person might know someone (implicitly, someone else) who might be interested in the job. Kimberly, an unemployed HR professional, offered a theory as to why this indirect strategy is preferred:

It's a little distasteful to call somebody up out of the blue and [ask], "Do you want this job?" Even though you have expressed no indication. It's like being a telemarketer but for jobs. "Did you know that you really want this garden hose? Did you know that you really want this job over here that you had expressed no desire for?"

She views the direct and unsolicited selling of job opportunities to passive candidates as distasteful or insulting because it implies that the candidate needs something unnecessary or that their current job is suboptimal.

It is also necessary to gain the trust of the target worker to get them to join an applicant pool. Introductory inquiries typically mention a mutual network connection in order to build that trust. The messages tend to be brief and offer the opportunity for low-stakes follow-up conversations. Rather than laying out all of the information at once, recruiters draw out the pitch across multiple interactions to pique a target's curiosity and give them time to warm up to the idea of changing jobs. Finally, recruiters tend to personalize their message and develop the relationship. As noted above, agency recruiter Brian chose to call targets rather than email them in order to have a more personalized conversation. Having multiple conversations over time also helps to develop rapport between the recruiter and the recruited.

Despite these efforts, attempts to woo passive candidates are prone to failure. In the words of agency recruiter Caitlin:

Sometimes you'll find what we call 'tire kickers' ... You'll reach out to ... a passive candidate and they'll say, "Maybe I'd be interested. Let me hear more about it." You tell them more about it and they'll [say]: "Yeah, sure, I'll do an interview." They'll go through the whole process and at the end of the day you realize they were never going to want to change jobs. They either got a kick out of 
[the idea that] "somebody was interested in me, that was fun" or "let me see what's out there but I really don't want to change where I am." Or maybe they were just wanting to get a counter offer from their current employer to up their salary.

Caitlin highlights the fact that identifying and wooing passive candidates is a "whole process," not a simple task, and that it can easily backfire. Candidates can string recruiters along by showing interest and then backing out at the last minute. This leads to a certain amount of frustration and ambivalence among even the most enthusiastic recruiters of passive candidates.

\section{Hunting for Purple Squirrels}

Another source of frustration among the most active recruiters is the fact that they are frequently held responsible for sourcing and attracting "purple squirrels." Kimberly offered her definition of purple squirrels:

If you're looking for something really specific like you need someone with $\mathrm{X}, \mathrm{Y}$ and $\mathrm{Z}$ skillset that's been in the industry for 10 years. ... You've got to dig for that needle in the haystack.

Purple squirrels are potential job candidates who have a set of characteristics that is so extensive and rare that they are nearly impossible to identify. Although Kimberly defines purple squirrels as having a very unique set of skills and industry-specific experience, other characteristics may also be involved. Margaret mentioned how the status of educational institutions can be a sticking point for hiring managers: "They have to have gone to a good school or a big school or a top 100 business school or something like that." Employers also frequently rely on abstract notions of the ideal person to fill a position, often based on characteristics of the prior incumbent. Sandra, a recruiter from a large energy company, offered an example:

If someone has been with the company for 20 years and then they retire, over that 20 years they may have worked in four different departments, had a totally different background, and learned so many things along the way. The hiring manager may be trying to replace that person with someone else just like them not understanding that that person is a creation that we have developed over 20 years. You can't go out in the street 
and find another person like that because they had a wealth of knowledge accumulated over time.

Here the characteristics of individuals employed within a given job have merged, over time, with the requirements for that job. Sandra's example emphasizes accumulated firm-specific knowledge and experience, but it is not difficult to imagine that other incumbent qualities might affect notions of the ideal replacement. For instance, Betty noted that sometimes, "the client calls you and they want this ideal person. Somebody wants a soul mate." Personality as well as social/cultural background of previous incumbents may therefore influence the expectations of new hires.

Purple squirrels represent a mounting difficulty for individuals in the recruiting field, as the lists of job requirements that recruiters receive from hiring managers have become longer and more specific over time. Patricia commented on reasons for this change.

The increased use of online tools has grown the pool of candidates to the point where managers definitely feel like they can find the perfect fit. "Well, there's got to be somebody out there that has five years' experience in programming, has done cloud computing, has server administration"... They have a laundry list, grocery list of things that they want. I think that having these online resources [makes people think], "Oh, maybe you can find it." ... The purple squirrel has definitely become more something managers think they can have because they see this huge database and they think, "There's got to be somebody in there. It's magic, if I just push a button, they'll pop out."

Patricia's reference to a "grocery list" depicts the Internet as a supermarket where employers can engage in detailed scans for their ideal workforce. She suggests that the increased availability of online information about workers has allowed hiring managers to shift from seeking an adequate fit for a job opening to expecting an ideal match. In other words, high candidate volume gives managers the opportunity to be choosy. Sandra explained: "The hiring managers, they don't have to settle because they're given more options and so they're able to select the best fit as opposed to the person [who] is available." Ruth, a part time recruiter nearing retirement age, offered a 
similar explanation: "Companies...think that, 'Oh, there are so many good people out there we can find the perfect fit.' Perfect."

Rising expectations may also serve as a tool for managing the rising applicant tide. For example, Patricia explained, 'Now you've got all these online sources and you could send them 2,500 candidates that have microbiology in their résumé and that's not solving anything." She is suggesting that when application volume grows, employers need more precise job requirements to whittle candidate pools down to manageable numbers. While this pragmatic approach seems to be a plausible response to the increased applicant flow, it does not explain why hiring managers are loathe to loosen job requirements when applicant pools are relatively dry. Margaret also claimed that the increasing volume of information online has contributed to a broader aversion to risk and a pattern of inflexibility with regard to job requirements that extends across the job market.

Many of the interviewees expressed concerns about the movement toward increased specialization and the significant challenges that it creates for the workforce. Susan's comment provides a representative example of this sentiment. "People are going to need to get more and more focused and specialized and, 'What are you the expert in?' Eventually, we'll all be freelancers. That's a little scary, but lots of candidates think that way." For Susan, the most disturbing aspect was the increased job insecurity that this shift brought about. Several other interviewees also thought that most jobs would be contract-only within the next few decades. Susan argued that operating as a contract worker required a specific mindset or personality that facilitated entrepreneurial self-promotion. As only a portion of the workforce possesses such traits, she felt that many individuals (especially introverts) would fare poorly in future job markets. 


\section{MIDDLE-GROUND PRACTICES}

The mass posting and targeted recruitment activities described thus far represent two frequently practiced polarities in market strategy. Our interviews also revealed evidence of middle-ground practices that combine features of both strategies. One middle-ground practice can be described as "niche" rather than "mass" posting. Recruiters advertise openings to audiences of active job seekers, but rather than Monster or Indeed they use specialized "niche" job boards run by professional, occupational, and/or identity-based affinity groups, industry associations, industry and professional media companies, or post-secondary schools. Savita, a university staff recruiting manager, described several websites she used in posting for information technology (e.g., Dice.com) and executive-level jobs (e.g., Ladders.com). Recruiters value this strategy of niche-posting because it attracts a more specialized and suitable candidate pool, and posting on some niche sites is free of charge.

A second middle-ground practice entails recruiting passive candidates in groups rather than individually. This batch-sourcing involves some online communication, but the most important contact is often face-to-face. Randall, a hospital HR manager, described hosting events to attract nurses:

We had an event [at a high-end local hotel], and it was an educational event, but it was also a recruitment event. We had nice food, had childcare available ... They got educational credits for the classes that were offered, which were general topics, and then while they were there had opportunity to meet with managers, interact. Very successful—out of that particular event [and another in a different location] ... I think we got 125 nurses.

Few occupations merited the elaborate events hosted for nurses, but many specialized recruiters sourced passive talent through active participation in outside groups. For example, IT recruiting manager Jessica volunteered at monthly meetings of a group for Women in Technology, which proved to be a useful recruiting opportunity, despite the esoteric content: "my eyes glaze over, 
but I get to meet people and I'll bring job descriptions with me." These batch-sourcing strategies are useful for accessing large pools of qualified candidates, but due to the significant costs and effort, these strategies are generally employed only in high-demand fields and where recruiters have numerous or ongoing openings.

A final middle ground strategy involves sourcing active job seekers rather than passive candidates. Lisa, a recruiting manager at a large financial services firm, described how she finds candidates with résumés listed on a mass posting website:

I may search for a candidate on Indeed and say 'Hey, I have a good opportunity, here is the link to apply' ... Even though they're applying directly to the [applicant tracking system], it's still someone I direct-sourced, and I'm most likely to reach out to them and schedule some time to talk to them and screen them.

This strategy seems to be used by recruiters whose mass posting strategies failed. They abandon posting job ads to the sites, but use them to identify and recruit active job seekers. The recruiters that we talked to found this practice to be superior to the mass posting approach for finding specialized talent. However, it requires significant time and effort. Vera, an HR generalist at an IT firm, noted that this practice involves sifting through out of date résumés and lack of interest among targets. Ultimately, she concluded that it was not useful for her: "you would call twenty people to get one person to call you back, and then at end the day it was just too time consuming and no results."

Niche-posting, batch-sourcing, and sourcing active job seekers are three examples of middle-ground strategies. ${ }^{2}$ Though middle-range practices are diverse, they can be characterized overall as requiring more upfront search effort than mass posting, but also a higher applicant volume and hence more screening and sorting than in the individual passive talent market.

\footnotetext{
${ }^{2}$ This is not an exhaustive list of middle ground practices. Others may include soliciting employee referrals, contacting former employees or previous job applicants, and actively cultivating social networks and "talent pipelines."
} 
Though all involve digital communication in some capacity, many seem to rely less exclusively on Internet-based search tools and more on in-person communication than is the case with mass posting and sourcing passive talent. There also appears to be a greater emphasis on participating in and even creating groups of various sorts (occupational, alumni, identity-based, etc.), which may require industrial or occupational expertise.

\section{IMPLICATIONS}

The ascendency of Internet search tools appears to have generated two distinct markets — one in which job seekers pitch application after application into the black hole of online job boards and the other where passive candidates are actively searched and sought. Although a muddled patchwork of practices lies in between, overall these processes represent novel form of labor market polarization. A number of conditions have contributed to this situation. First, the availability of online information has reduced labor market information asymmetries. Workers have greater knowledge about potential job openings and employers have greater knowledge of potential job applicants. Second, web applications and algorithmic tools have made it easier to advertise for jobs, apply for jobs, screen job applications, and recruit potential job candidates. These conditions have transformed not only the processes by which workers are matched to jobs, but also expectations for skill and fit. Access to more extensive knowledge about and connectivity to the labor force has allowed employers to ratchet up their skill expectations, helping to create a market for "purple squirrels" with highly specialized (and improbable) skill sets. But perceived worthiness extends beyond mere task performance. Employers interpret digital signals to determine the extent to which workers match subjective notions of "ideal performativity" (P. McDonald \& Thompson, 2016). Workers who meet consensus standards for ideal skills and performativity are extensively recruited for new employment opportunities. 
Those workers who lack ideal features face increased competition in the mass job posting market.

These features resemble those associated with "winner-take-all” markets (Frank \& Cook, 1996). Digital signifiers provide the basis for ranking the workforce and subtle differences in those perceived rankings can result in disparate employment outcomes. Recently, Fourcade and Healy (2017) argued that digital signals afford individuals with a form of capital ("ubercapital") that can be translated into economic rewards. ${ }^{3}$ These economic rewards are likely to accumulate for individuals with favored digital signals (see Merton, 1973; DiPrete \& Eirich, 2006). While the results presented here are consistent with these accounts, much remains unknown about the broader implications of online labor market segmentation. For example, the extent to which these changes have altered the overall supply of high quality employment remains uncertain. Does increased talent poaching enhance employment opportunities for one group at the expense of others or does it simply lead to an unending round of musical chairs - with much standing up, moving, and sitting down, but no chairs being removed? We think that there is sufficient reason for concern. In aggregate, the US has experienced declining labor force participation and job growth rates, leading economists to suggest that we have entered a new era of "jobless" recoveries (Burger \& Schwartz, 2018) and "secular stagnation” (Summers, 2015). While employers and policy makers have argued that sluggish hiring has much to do with a shortage of workers with necessary skills, empirical research offers little evidence of a skills gap (Cappelli, 2015). Rather, overqualification for work has increased substantially over time (Vaisey, 2006). Moreover, recent evidence suggests that employer preference for passive talent was unaffected by the Great Recession in 2007; avoidance of unemployed workers went on unabated despite

\footnotetext{
${ }^{3}$ In line with Weeden \& Grusky (2014), one might also argue that ubercapital represents a new employment rent for elite workers in contemporary labor markets.
} 
increased labor supply (Coverdill \& Finlay, 2017). All of this suggests that rising skill expectations and preferences for passive talent could put downward pressure on aggregate hiring patterns.

These concerns are further exacerbated by the potential expansion of the passive talent market. While changing jobs without engaging in a job search has long been reported (Granovetter, 1974), formalized "headhunting" was typically reserved for executive search prior to the Internet (Finlay \& Coverdill, 2002). The ease of access to LinkedIn and online search tools appears to have expanded recruitment of passive candidates to a wider range of occupational fields, although they continue to be hired more for high wage positions. Importantly, we found a crucial difference in the ways that passive talent is perceived and recruited across employment sectors. Third party staffing and recruiting agencies view passive candidates very favorably and actively seek to recruit these individuals. These types of organizations frame passive talent as potential candidates as a key selling point for their services - they market themselves based on their ability to tap into hidden talent pools (Coverdill \& Finlay, 2017). By contrast, non-profit and government organizations mostly avoid the passive market. Consistent with prior research on hiring based on interpersonal networks, these types of organizations are driven less by profit motivations than by the need to generate external legitimacy regarding equity, universalism, and transparency (Marsden, 2001; DiMaggio \& Powell, 1991). Pursuing passive talent contradicts those ideals because it benefits workers who are not in need of employment and involves poaching talent from other organizations, which may violate personal ethics and industrial norms (e.g., non-poaching agreements between institutions in the same educational system). This variability highlights the way that institutional context shapes the social construction of job matching practices. 
The present study also advances research on signaling and stigmatization. Previous research on this topic has addressed unemployment stigma (Eriksson \& Rooth, 2014; Weisshaar 2018) and the "scarring" consequences of unemployment (Gangl, 2006). The interview data presented here confirms that unemployment can serve as a powerful indicator of candidate quality in the eyes of organizational gatekeepers, comparable to how elite candidates' attendance at less prestigious educational institutions may be seen as symbols of intellectual or moral failures (Rivera, 2016). Employers also make inferences about candidates based on the extent to which they are actively looking for work. ${ }^{4}$ The most sought after candidates are not merely those who are employed, but those who are also not actively looking for new employment. Active job seeking carries a negative stigma that raises questions about their job performance (such as whether they will be troublemakers or team players). The stigma of active search is borne out by research on the employment benefits associated with non-searching (McDonald, 2015) and has the potential to reshape theories of labor market matching and stratification (McDonald, 2010). Our research also points out that workers engage in activities (such as updating their LinkedIn status) to signal their willingness to change jobs while also maintaining their passivity. Much more can be learned about how that process unfolds and how it is perceived by employment intermediaries.

Recent research has also examined how employers interpret and value signals of cultural similarity and mastery, especially as part of résumés and in-person interviews in elite labor market contexts (Rivera, 2016). Cultural signaling is an essential feature of the online market as well. While scholars have begun to study job seekers' strategies for developing online personas

\footnotetext{
${ }^{4}$ The extent to which unemployment may be overcome by candidates' exhibition of elite characteristics remains unclear. However, Kevin's experience suggests that the stigma of unemployment alone may transfer an otherwise elite candidate into the pool of undesirables.
} 
or "brands" (Sharone, 2017; Gershon, 2017), relatively little is known about how digital signals are perceived and used as part of the applicant screening process. HR employs a variety of technological strategies to review applicant information, including the use of filtering tools accessed directly through mass posting boards, customized keyword searching through ATS software systems, or specialized algorithmic hiring recommendations from third party vendors (Horton, 2016). HR also frequently engages in "cybervetting," which involves reviewing online information from personal social media sources, Google searches, and credit reports to inform hiring and recruitment decisions (Kiviat, Forthcoming; Berger \& Zickar, 2016). Preliminary research on this topic implies that these types of digital evaluation processes, which are commonly sold as being bias-free, impose major hardships for marginalized groups in society (O’Neil, 2016; Eubanks, 2017). Our research similarly suggests that the sourcing of purple squirrels raises the bar for online job candidates so that only the most privileged can transcend it. Future research is needed to better understand how this work is done, what signals are rewarded/penalized, and what the broader consequences are for labor market stratification.

Future research should also consider the role that interpersonal and online networks play in these two distinctive markets. Gershon (2017) recently argued that the Internet has transformed the value of interpersonal networks in the labor market. Previously, weak ties gained their strength from their non-redundancy, which afforded greater access to unique information about employment opportunities (Granovetter, 1973). Enhanced exposure to employment information brought on by mass posting websites reduced the premium associated with accessing job leads. The problem shifted from finding a good job to being hired into one. In the black hole market, insider contacts may be more useful than weak ties, especially to the extent that they can help workers to bypass ATS screening technology. In the market for passive talent, access to 
other types of network contacts may be especially beneficial (such as connections that span structural holes: Burt, 1991). In short, different network logics are likely to pervade the different online labor markets described here. Future research should examine those logics as well as the labor market conditions under which different types of contacts and network resources are particularly efficacious. The present study provides a useful starting point for these and other future investigations. 


\section{REFERENCES}

Arthur, M. B., \& Rousseau, D. M. (1996). The boundaryless career: A new employment principle for a new organizational era. Oxford: Oxford University Press.

Autor, D. H. (2001). Wiring the Labor Market. Journal of Economic Perspectives, 15(1), 25-40.

Autor, D. H., Katz, L. F., \& Kearney, M. S. (2008). Trends in US Wage Inequality: Revising the Revisionists. Review of Economics and Statistics, 90(2), 300-323.

Berger, J. L., \& Zickar, M. J. (2016). Theoretical Propositions About Cybervetting: A Common Antecedents Model. In R. N. Landers \& G. B. Schmidt (Eds.), Social Media in Employee Selection and Recruitment: Theory, Practice, and Current Challenges (pp. 43-58). Switzerland: Springer.

Bonet, R., Cappelli, P., \& Hamori, M. (2013). Labor Market Intermediaries and the New Paradigm for Human Resources. Academy of Management Annals, 7(1), 341-392.

Bound, J., \& Johnson, G. (1992). Changes in the Structure of Wages in the 1980s: An Evaluation of Alternative Explanations. American Economic Review, 82(3), 371-392.

Burger, J. D., \& Schwartz, J. S. (2018). Jobless Recoveries: Stagnation or Structural Change? Economic Inquiry, 56(2), 709-723.

Burke, M., \& Kraut, R. (2013). Using Facebook after losing a job: Differential benefits of strong and weak ties. In Proceedings of the 2013 conference on Computer supported cooperative work (pp. 1419-1430). ACM. Retrieved from http://dl.acm.org/citation.cfm?id=2441936

Burt, R. S. (1992). Structural holes: the social structure of competition. Cambridge, MA: Harvard University Press. 
Cappelli, P. (2001). Making the most of on-line recruiting. Harvard Business Review, 79(3), $139-+$.

Cappelli, P. H. (2015). Skill Gaps, Skill Shortages, and Skill Mismatches Evidence and Arguments for the United States. ILR Review, 68(2), 251-290.

Carr, C. T. (2016). An Uncertainty Reduction Approach to Applicant Information-Seeking in Social Media: Effects on Attributions and Hiring. In R. N. Landers \& G. B. Schmidt (Eds.), Social Media in Employee Selection and Recruitment: Theory, Practice, and Current Challenges (pp. 59-78). Switzerland: Springer.

Coverdill, J. E. \& Finlay, W. (2017). High Tech and High Touch: Headhunting, Technology, and Economic Transformation. Ithaca, NY: Cornell/ILR Press.

DiMaggio, P., \& Bonikowski, B. (2008). Make Money Surfing the Web? The Impact of Internet Use on the Earnings of U.S. Workers. American Sociological Review, 73(2), 227-250.

DiMaggio, P., Hargittai, E., Neuman, W. R., \& Robinson, J. P. (2001). Social Implications of the Internet. Annual Review of Sociology, 27(1), 307-336.

DiMaggio, P., \& Powell, W. (1991). The iron cage revisited: Institutional isomorphism and collective rationality in organizational fields. In W. Powell \& P. DiMaggio (Eds.), The New Institutionalism in Organizational Analysis (pp. 63-82). Chicago: University of Chicago Press.

DiPrete, T. A., \& Eirich, G. M. (2006). Cumulative Advantage as a Mechanism for Inequality: A Review of Theoretical and Empirical Developments. Annual Review of Sociology, 32(1), 271-297.

Doeringer, P. B., \& Piore, M. J. (1971). Internal Labor Markets and Manpower Analysis. Armonk: M.E. Sharpe, Inc. 
Eriksson, S., \& Rooth, D. (2014). Do Employers Use Unemployment as a Sorting Criterion When Hiring? Evidence from a Field Experiment. American Economic Review, 104(3), 1014-1039.

Eubanks, V. (2017). Automating Inequality: How High-Tech Tools Profile, Police, and Punish the Poor. NY: St. Martin's Press.

Faliagka, E., Tsakalidis, A., \& Tzimas, G. (2012). An integrated e-recruitment system for automated personality mining and applicant ranking. Internet Research, 22(5), 551-568.

Feldman, D. C., \& Klaas, B. S. (2002). Internet job hunting: A field study of applicant experiences with on-line recruiting. Human Resource Management, 41(2), 175-192.

Finlay, W. \& Coverdill, J. E. (2002). Headhunters: Matchmaking in the Labor Market. Ithaca: Cornell University Press.

Fountain, C. M. (2005). Finding a Job in the Internet Age. Social Forces, 83(3), 1235-1262.

Fourcade, M., \& Healy, K. (2017). Seeing like a market. Socio-Economic Review, 15(1), 9-29.

Frank, R. H., \& Cook, P. J. (1996). The Winner-Take-All Society: Why the Few at the Top Get So Much More Than the Rest of Us. New York: Penguin Books.

Frank, R. H., \& Cook, P. J. (2013). Winner-Take-All Markets. Studies in Microeconomics, 1(2), $131-154$.

Freeman, R. B. (2002). The labour market in the new information economy. Oxford Review of Economic Policy, 18(3), 288-305.

Gangl, M. (2006). Scar effects of unemployment: An assessment of institutional complementarities. American Sociological Review, 71(6), 986-1013.

Gershon, I. (2017). Down and out in the new economy: How people find (or don't find) work today. University of Chicago Press. 
Granovetter, M. S. (1973). The Strength of Weak Ties. American Journal of Sociology, 78(6), 1360-1380.

Granovetter, M. S. (1974). Getting a job. A study of contacts and careers. Cambridge, MA: Harvard University Press.

Green, A. E., Li, Y., Owen, D., \& de Hoyos, M. (2012). Inequalities in use of the Internet for job search: similarities and contrasts by economic status in Great Britain. Environment and Planning A, 44(10), 2344-2358.

Hanley, C. (2014). Putting the Bias in Skill-Biased Technological Change? A Relational Perspective on White-Collar Automation at General Electric. American Behavioral Scientist, 58(3), 400-415.

Hargittai, E. (2011). The digital reproduction of inequality. In D. B. Grusky \& S. Szelenyi (Eds.), Social stratification (pp. 660-670). Boulder, CO: Westview Press.

Hess-Biber, S. N., \& Leavy, P. (2011). The Practice of Qualitative Research (2 ${ }^{\text {nd }}$ edition). Los Angeles: Sage.

Horton, J. J. (2016). The Effects of Algorithmic Labor Market Recommendations: Evidence from a Field Experiment. Journal of Labor Economics, 35(2), 354-385.

Hudson, K. (2007). The new labor market segmentation: Labor market dualism in the new economy. Social Science Research, 36(1), 286-312.

Kiviat, B. (Forthcoming). The art of deciding with data: evidence from how employers translate credit reports into hiring decisions. Socio-Economic Review. https://doi.org/10.1093/ser/mwx030 
Klotz, A. C., da Motta Veiga, S. P., Buckley, M. R., \& Gavin, M. B. (2013). The role of trustworthiness in recruitment and selection: A review and guide for future research. Journal of Organizational Behavior, 34(S1), S104-S119.

Kuhn, P., \& Skuterud, M. (2004). Internet Job Search and Unemployment Durations. American Economic Review, 94(1), 218-232.

Marsden, P. (2001). Interpersonal ties, social capital, and employer staffing practices. In N. Lin, K. Cook, \& R.S. Burt (Eds.), Social Capital: Theory and Research (pp. 105-125). New Brunswick, NJ: Transaction Publishers.

McDonald, P., \& Thompson, P. (2016). Social Media(tion) and the Reshaping of Public/Private Boundaries in Employment Relations. International Journal of Management Reviews, $18(1), 69-84$.

McDonald, S. (2010). Right place, right time: serendipity and informal job matching. SocioEconomic Review, 8(2), 307-331.

McDonald, S. (2015). Network effects across the earnings distribution: Payoffs to visible and invisible job finding assistance. Social Science Research, 49, 299-313.

McDonald, S., \& Crew, R. E., Jr. (2006). Welfare to web to work: Internet job searching among former welfare clients in Florida. J. Soc. \& Soc. Welfare, 33, 239.

Merton R. K. (1973). The Matthew effect in science. In N. W. Storer (Ed.), The Sociology of Science (pp. 439-59). Chicago: University of Chicago Press.

Powell, W. W. (1990). Neither Market nor Hierarchy: Network Forms of Organization. In B. M. Staw \& L. L. Cummings (Eds.), Research on Organizational Behavior (Vol. 12, pp. 295336). Greenwich, CT: JAI Press. 
Nakamura, A. O., Shaw, K. L., Freeman, R. B., Nakamura, E., \& Pyman, A. (2009). Jobs online. In D. H. Autor (Ed.), Studies of labor market intermediation (pp. 27-65). Chicago: University of Chicago Press.

Niles, S., \& Hanson, S. (2003). The geographies of online job search: preliminary findings from Worcester, MA. Environment and Planning A, 35(7), 1223 - 1243.

O’Neil, C. (2016). Weapons of math destruction: How big data increases inequality and threatens democracy. New York: Crown Books.

Pew Research Center. (2017). Internet/Broadband Fact Sheet. Retrieved from http://www.pewinternet.org/fact-sheet/internet-broadband/

Powell, W. W. (1990). Neither Market nor Hierarchy: Network Forms of Organization. In B. M. Staw \& L. L. Cummings (Eds.), Research on Organizational Behavior (Vol. 12, pp. 295336). Greenwich, CT: JAI Press.

Rivera, L. A. (2016). Pedigree: How Elite Students Get Elite Jobs. Princeton, NJ: Princeton University Press.

Ruggs, E. N., Walker, S. S., Blanchard, A., \& Gur, S. (2016). Online Exclusion: Biases That May Arise When Using Social Media in Talent Acquisition. In R. N. Landers \& G. B. Schmidt (Eds.), Social Media in Employee Selection and Recruitment: Theory, Practice, and Current Challenges (pp. 289-306). Switzerland: Springer.

Sharone, O. (2017). LinkedIn or LinkedOut? How Social Networking Sites are Reshaping the Labor Market. Research in the Sociology of Work, 30, 1-31.

SHRM. (2016). Survey Findings: Using Social Media for Talent Acquisition: Recruitment and Screening. Retrieved from https://www.shrm.org/ResourcesAndTools/hr-topics/talentacquisition/Pages/Using-Social-Media-Find-Passive-Candidates.aspx 
Smith, A. (2015). Searching for work in the digital era. Pew Research Center. Retrieved from www.pewinternet.org/2015/11/19/searching-for-work-in-the-digital-era/

Stoughton, J. W., Thompson, L. F., \& Meade, A. W. (2013). Big Five Personality Traits Reflected in Job Applicants' Social Media Postings. Cyberpsychology Behavior and Social Networking, 16(11), 800-805.

Summers, L. H. (2015). Demand Side Secular Stagnation. American Economic Review, 105(5), $60-65$.

Suvankulov, F., Chi Keung Lau, M., \& Ho Chi Chau, F. (2012). Job search on the internet and its outcome. Internet Research, 22(3), 298-317.

Vaisey, S. (2006). Education and its discontents: Overqualification in America, 1972-2002. Social Forces 85: 835-864.

Van Hoye, G., van Hooft, E. A. J., \& Lievens, F. (2009). Networking as a job search behaviour: A social network perspective. Journal of Occupational and Organizational Psychology, 82(3), 661-682.

Viswanath, K., Kosicki, G. M., Fredin, E. S., \& Park, E. (2000). Local Community Ties, Community-Boundedness, and Local Public Affairs Knowledge Gaps. Communication Research, 27(1), 27-50.

Walther, J. B. (1996). Computer-Mediated Communication: Impersonal, Interpersonal, and Hyperpersonal Interaction. Communication Research, 23(1), 3-43.

Weeden, K. A., \& Grusky, D. B. (2014). Inequality and Market Failure. American Behavioral Scientist, 58(3), 473-491.

Weisshaar, K. (2018). From Opt Out to Blocked Out: The Challenges for Labor Market Re-entry after Family-Related Employment Lapses. American Sociological Review, 83(1), 34-60. 


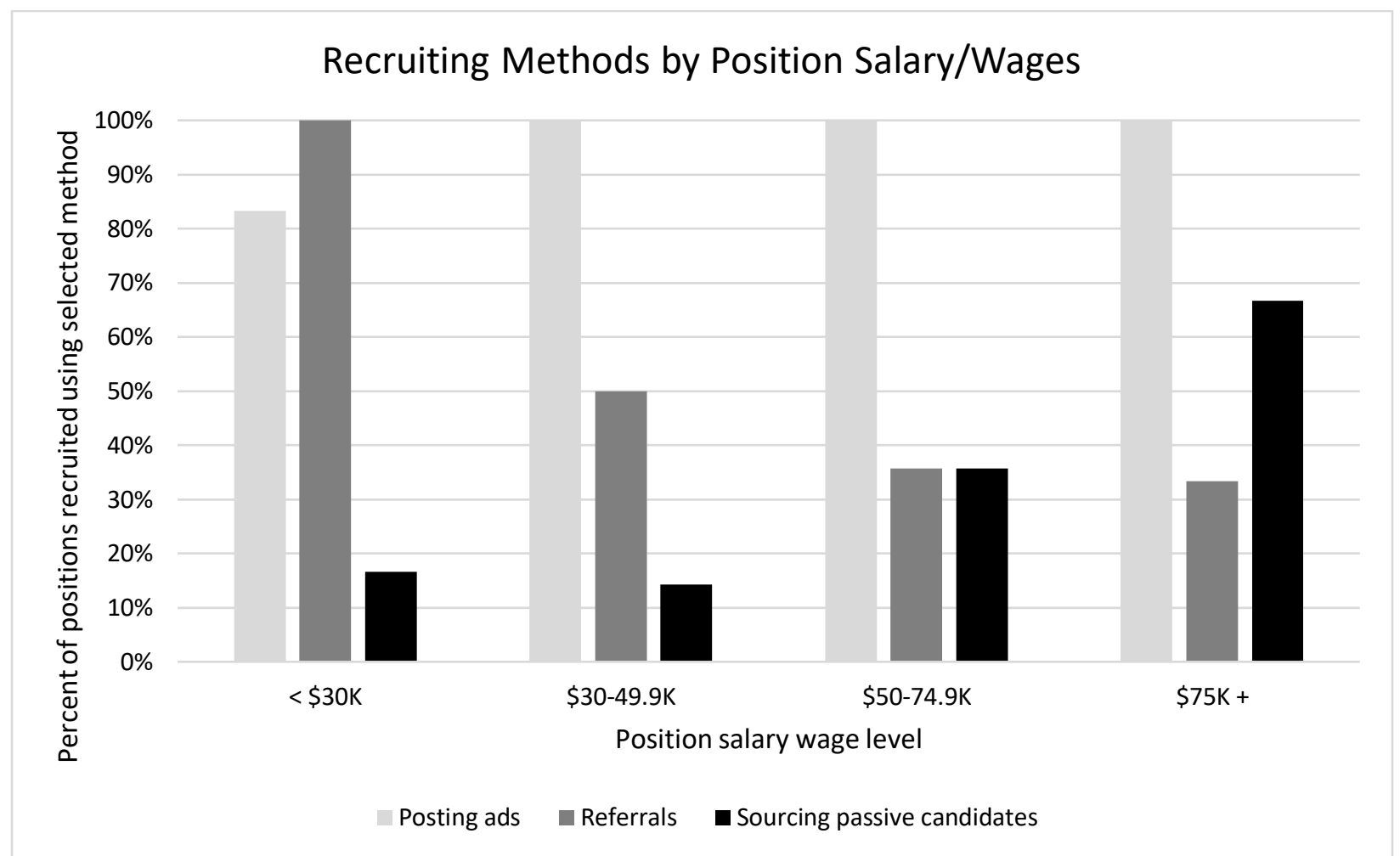

Figure 1. Recruitment methods by salary/wages

Note: Atlanta data only. 46 positions from 26 interviews 


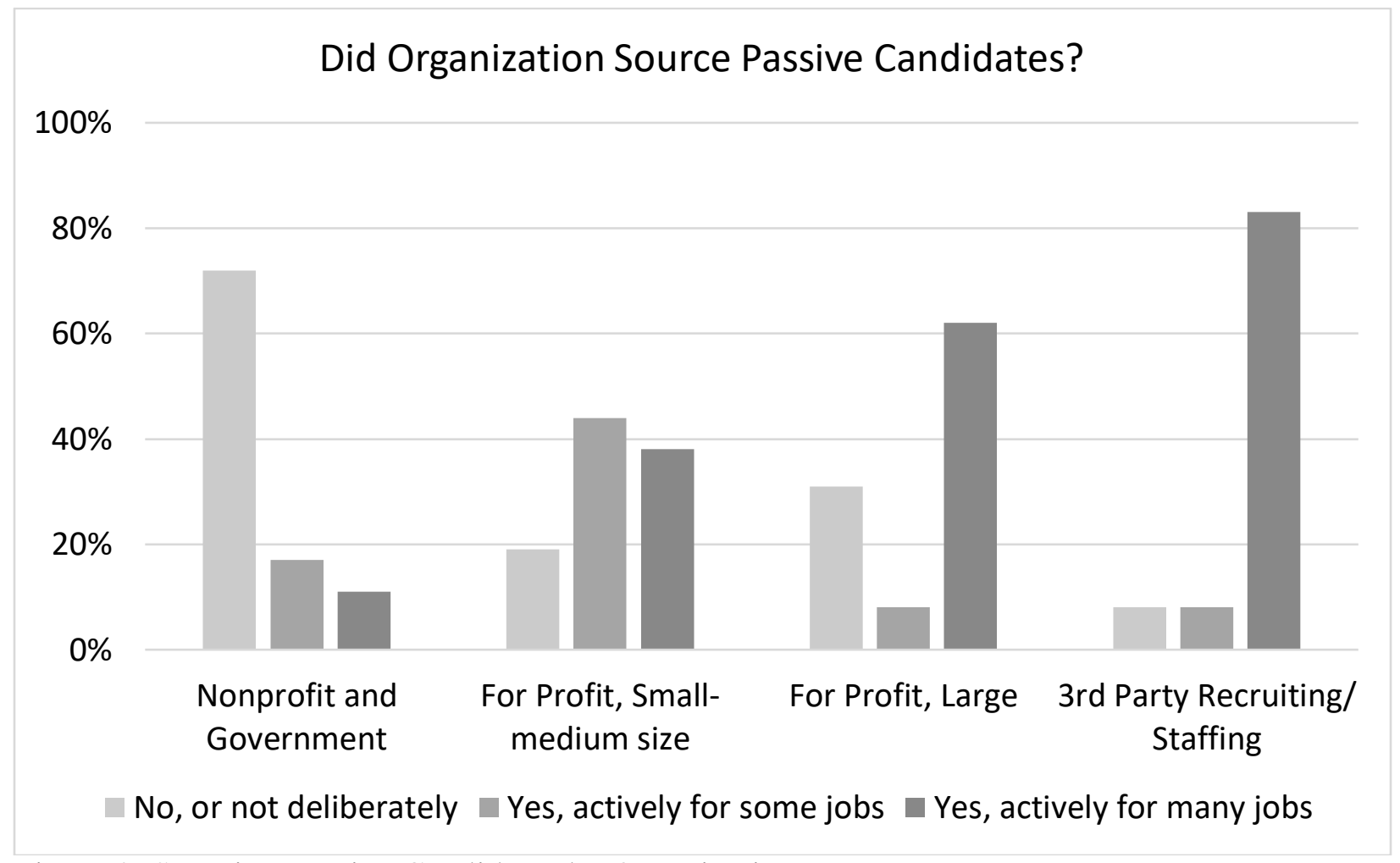

Figure 2. Sourcing Passive Candidates by Organization Type 
Appendix

Table 1. Interviewee Characteristics

\begin{tabular}{|c|c|c|c|c|c|c|c|}
\hline \multirow{2}{*}{$\begin{array}{l}\text { Pseudo- } \\
\text { nym }\end{array}$} & \multirow[b]{2}{*}{ City } & \multirow[b]{2}{*}{ Gender } & \multirow[b]{2}{*}{ Race } & \multirow[b]{2}{*}{ Age } & \multirow[b]{2}{*}{ HR Role } & \multicolumn{2}{|c|}{ Primary Organization } \\
\hline & & & & & & Type & Size* \\
\hline Alicia & Atlanta & $\mathrm{F}$ & White & $40 \mathrm{~s}$ & Recruiting & Professional svcs. firm & Medium \\
\hline Amy & Atlanta & $\mathrm{F}$ & White & $30 \mathrm{~s}$ & Generalist & Utility nonprofit & Medium \\
\hline Angela & Atlanta & $\mathrm{F}$ & Black & $30 \mathrm{~s}$ & Generalist & Health services firm & Large \\
\hline Barbara & Raleigh & $\mathrm{F}$ & Black & $40 \mathrm{~s}$ & Generalist & College/univ., private & Very large \\
\hline Betty & Raleigh & $\mathrm{F}$ & White & $20 \mathrm{~s}$ & Generalist & Recruiting firm & Small \\
\hline Brandy & Atlanta & $\mathrm{F}$ & White & $20 \mathrm{~s}$ & Recruiting & College/univ., private & Large \\
\hline Brian & Raleigh & M & White & $30 \mathrm{~s}$ & Recruiting & Recruiting firm & Small \\
\hline Caitlin & Atlanta & $\mathrm{F}$ & White & $30 \mathrm{~s}$ & Recruiting & Recruiting firm & Small \\
\hline Carol & Raleigh & $\mathrm{F}$ & White & $30 \mathrm{~s}$ & Recruiting & Health sves nonprofit & Medium \\
\hline Celine & Atlanta & $\mathrm{F}$ & Black & $30 \mathrm{~s}$ & Recruiting & Professional svcs. firm & Large \\
\hline Charles & Raleigh & M & White & $60 \mathrm{~s}$ & Generalist & Education nonprofit & Small \\
\hline Dan & Raleigh & M & White & $40 \mathrm{~s}$ & Recruiting & Recruiting firm & Very large \\
\hline Danielle & Atlanta & $\mathrm{F}$ & Black & $20 \mathrm{~s}$ & Generalist & IT firm & Medium \\
\hline Dawn & Atlanta & $\mathrm{F}$ & White & $50 \mathrm{~s}$ & Recruiting & Recruiting firm & Small \\
\hline Deborah & Atlanta & $\mathrm{F}$ & White & $60 \mathrm{~s}$ & Generalist & Engineering firm & Medium \\
\hline Donna & Raleigh & $\mathrm{F}$ & White & $40 \mathrm{~s}$ & Consulting & Recruiting firm & Small \\
\hline Dorothy & Raleigh & $\mathrm{F}$ & Black & $20 \mathrm{~s}$ & Recruiting & Manufacturing firm & Very large \\
\hline Edward & Raleigh & M & Other & $30 \mathrm{~s}$ & Recruiting & Health services firm & Medium \\
\hline Emily & Raleigh & $\mathrm{F}$ & White & $50 \mathrm{~s}$ & Recruiting & Engineering firm & Medium \\
\hline Heather & Atlanta & $\mathrm{F}$ & White & $30 \mathrm{~s}$ & Recruiting & Restaurant chain & Very large \\
\hline Helen & Raleigh & $\mathrm{F}$ & White & $40 \mathrm{~s}$ & Generalist & Telecomm. firm & Large \\
\hline Jeanette & Atlanta & $\mathrm{F}$ & Black & $40 \mathrm{~s}$ & Generalist & Church & Medium \\
\hline Jessica & Atlanta & $\mathrm{F}$ & White & $40 \mathrm{~s}$ & Generalist & IT firm & Small \\
\hline Joe & Raleigh & M & White & $30 \mathrm{~s}$ & Recruiting & College/univ., public & Very large \\
\hline John & Atlanta & M & White & $40 \mathrm{~s}$ & Recruiting & Utility company & Very large \\
\hline Jonathan & Raleigh & M & Black & $50 \mathrm{~s}$ & Generalist & College/univ., private & Very large \\
\hline Kenneth & Raleigh & M & Black & $40 \mathrm{~s}$ & Consulting & Recruiting firm & Very large \\
\hline Kevin & Raleigh & M & White & $50 \mathrm{~s}$ & Generalist & Utility company & Medium \\
\hline Kimberly & Raleigh & $\mathrm{F}$ & White & $30 \mathrm{~s}$ & Generalist & IT firm & Small \\
\hline Larry & Atlanta & M & White & $40 \mathrm{~s}$ & Generalist & Retail firm & Very large \\
\hline Lauren & Atlanta & $\mathrm{F}$ & White & $30 \mathrm{~s}$ & Generalist & Utility nonprofit & Medium \\
\hline Linda & Raleigh & $\mathrm{F}$ & White & $40 \mathrm{~s}$ & Generalist & Profl svcs. nonprofit & Small \\
\hline Lisa & Raleigh & $\mathrm{F}$ & White & $30 \mathrm{~s}$ & Generalist & Manufacturing firm & Very large \\
\hline Lyn & Atlanta & $\mathrm{F}$ & Black & $30 \mathrm{~s}$ & Generalist & State agency & Medium \\
\hline Margaret & Raleigh & $\mathrm{F}$ & White & $50 \mathrm{~s}$ & Recruiting & Professional sves. firm & Small \\
\hline Mark & Raleigh & M & White & $40 \mathrm{~s}$ & Recruiting & Professional svcs. firm & Very large \\
\hline Mary & Raleigh & $\mathrm{F}$ & White & $50 \mathrm{~s}$ & Generalist & Real estate firm & Small \\
\hline Mitchell & Atlanta & M & Black & $60 \mathrm{~s}$ & Generalist & State agency & Large \\
\hline
\end{tabular}




\begin{tabular}{|c|c|c|c|c|c|c|c|}
\hline Monica & Atlanta & $\mathrm{F}$ & Other & $40 \mathrm{~s}$ & Recruiting & Professional svcs. firm & Small \\
\hline Nancy & Raleigh & $\mathrm{F}$ & White & $20 \mathrm{~s}$ & Recruiting & Recruiting firm & Large \\
\hline Patricia & Raleigh & $\mathrm{F}$ & White & $40 \mathrm{~s}$ & Recruiting & Health services firm & Very large \\
\hline Randall & Atlanta & M & White & $60 \mathrm{~s}$ & Generalist & Health services firm & Very large \\
\hline Rick & Raleigh & M & White & $40 \mathrm{~s}$ & Recruiting & College/univ., private & Very large \\
\hline Robert & Raleigh & M & White & $50 \mathrm{~s}$ & Recruiting & College/univ., public & Very large \\
\hline Ruby & Atlanta & $\mathrm{F}$ & Black & $40 \mathrm{~s}$ & Generalist & Publishing firm & Medium \\
\hline Ruth & Raleigh & $\mathrm{F}$ & White & $50 \mathrm{~s}$ & Generalist & Professional svcs. firm & Small \\
\hline Ryan & Atlanta & M & White & $30 \mathrm{~s}$ & Recruiting & Recruiting firm & Small \\
\hline Samantha & Atlanta & $\mathrm{F}$ & White & $20 \mathrm{~s}$ & Recruiting & Recruiting firm & Very large \\
\hline Sandra & Raleigh & $\mathrm{F}$ & Black & $30 \mathrm{~s}$ & Recruiting & Manufacturing firm & Very large \\
\hline Sarah & Raleigh & $\mathrm{F}$ & White & $40 \mathrm{~s}$ & Recruiting & College/univ., private & Large \\
\hline Savita & Atlanta & $\mathrm{F}$ & Other & $30 \mathrm{~s}$ & Generalist & College/univ., public & Very large \\
\hline Sharon & Raleigh & $\mathrm{F}$ & White & $30 \mathrm{~s}$ & Generalist & Profl svcs. nonprofit & Medium \\
\hline Sonny & Raleigh & M & White & $40 \mathrm{~s}$ & Recruiting & Recruiting firm & Large \\
\hline Sophia & Raleigh & $\mathrm{F}$ & Other & $40 \mathrm{~s}$ & Generalist & Health services firm & Medium \\
\hline Stephanie & Atlanta & $\mathrm{F}$ & White & $20 \mathrm{~s}$ & Generalist & Manufacturing firm & Medium \\
\hline Susan & Raleigh & $\mathrm{F}$ & White & $50 \mathrm{~s}$ & Generalist & Professional svcs. firm & Medium \\
\hline Tanya & Atlanta & $\mathrm{F}$ & Other & $30 \mathrm{~s}$ & Generalist & Engineering firm & Medium \\
\hline Theresa & Atlanta & $\mathrm{F}$ & Black & $40 \mathrm{~s}$ & Recruiting & Business svcs. firm & Very large \\
\hline Tisha & Atlanta & $\mathrm{F}$ & Black & $30 \mathrm{~s}$ & Generalist & Environ. sves. nonprft. & Small \\
\hline Tracie & Atlanta & $\mathrm{F}$ & Black & $30 \mathrm{~s}$ & Generalist & Retail firm & Very large \\
\hline Vera & Atlanta & F & White & $30 \mathrm{~s}$ & Generalist & IT firm & Small \\
\hline
\end{tabular}

